\title{
Primary ovarian leiomyoma in young woman with premature ovarian failure
}

\author{
Vidhi Chaudhary ${ }^{1 *}$, Kiran Aggarwal', Anita Nangia ${ }^{2}$
}

\begin{abstract}
${ }^{1}$ Department of Obstetrics and Gynecology, ${ }^{2}$ Department of Pathology, Lady Hardinge Medical College, New Delhi, Delhi, India
\end{abstract}

Received: 22 July 2018

Accepted: 28 August 2018

\section{*Correspondence:}

Dr. Vidhi Chaudhary,

E-mail: drvidh@gmail.com

Copyright: () the author(s), publisher and licensee Medip Academy. This is an open-access article distributed under the terms of the Creative Commons Attribution Non-Commercial License, which permits unrestricted non-commercial use, distribution, and reproduction in any medium, provided the original work is properly cited.

\begin{abstract}
Authors present a rare case of primary ovarian leiomyoma in a young female with premature ovarian failure. A 39year-old female with premature ovarian failure presented with large unilateral adnexal mass, with mildly elevated CA-125 levels, underwent staging laparotomy where the left ovarian mass along with tubes was removed. Contralateral ovary and uterus were preserved. Final diagnosis was Primary ovarian leiomyoma on histopathology and immunohistochemical analysis. Preoperative diagnosis is difficult with solid ovarian tumors. In presence of mildly elevated CA-125 and negative tumor markers, ovarian leiomyoma must be considered as a differential diagnosis and conservative surgery be planned as these patients are desirous of future fertility options. Definitive diagnosis is confirmed by histopathology and immunohistochemical analysis.
\end{abstract}

Keywords: Ovarian leiomyoma, Ovarian tumors, Premature ovarian failure

\section{INTRODUCTION}

Leiomyoma of ovary is a rare solid tumor of the ovary with incidence in range of in range of $0.5-1 \%$ of all the benign ovarian tumors. ${ }^{1}$ Usual age of presentation is between 20-65 years. ${ }^{2}$ Ovarian leiomyomas are usually unilateral and commonly occur in premenopausal women as fibroids being estrogen dependent condition. ${ }^{3,4}$ These tumors are diagnosed incidentally with common features of abdominal discomfort and palpable mass. They may be asymptomatic in presentation. Few cases may present as acute abdomen, ascites, Meig's syndrome and hydronephrosis. ${ }^{5,6}$ Differential diagnoses are thecoma, fibroma, sclerosing stromal tumor, and leiomyosarcoma. Diagnostic modalities include ultrasound with better delineation with MRI. Final diagnosis is however with histopathology and immunohistochemical analysis using actin and vimentin stain which diffusely stains leiomyoma due to their mesenchymal origin.
In this study, authors report a case of a primary ovarian leiomyoma in a 37-year-old woman with premature ovarian failure where ovarian and uterine preservation was done so that future fertility options could be exercised either via invitro fertilization or surrogacy.

\section{CASE REPORT}

A 39-year-old female married for 10 years, came with complaints of mild discomfort in lower abdomen since 34 months. She had history of premature ovarian failure (POF) since last four years. Her previous menstrual cycles were regular. She had a history of infertility treatment with 3 cycles of intrauterine insemination. She had spontaneous cessation of menstruation. She had no history of vomiting, severe pain abdomen or fever and had no urinary or bowel discomfort. On examination vitals were stable with no pallor, pedal edema, icterus and lymphadenopathy. Chest and cardiovascular system were 
grossly normal. Per abdomen examination revealed $12 \mathrm{X} 10 \mathrm{~cm}$ mass occupying hypo agastric and right lumbar region with restricted mobility. Mass was nontender. Per speculum examination revealed nulliparous os with healthy vagina and cervix. On per vaginal examination, uterus was anteverted and bulky. Nontender, firm mass of $12 \times 12 \mathrm{~cm}$ was felt through right fornix with restricted mobility and was felt separately from uterus. Rectal mucosa was free on per rectal examination. Tumor markers were asked for and had CA 125-76 IU/L. Serum AFP 3.26ng/ml, CA 19-9-<2, LDH $133 \mathrm{IU} / \mathrm{L}$, beta $\mathrm{HCG}<1.2 \mathrm{Miu} / \mathrm{ml}$, Inhibin A $3.4 \mathrm{pg} / \mathrm{ml}$, and CEA 0.68, all were within normal range. Her LH 48 $\mathrm{Miu} / \mathrm{ml}$ and FSH $21 \mathrm{Miu} / \mathrm{ml}$ levels were near menopausal range.

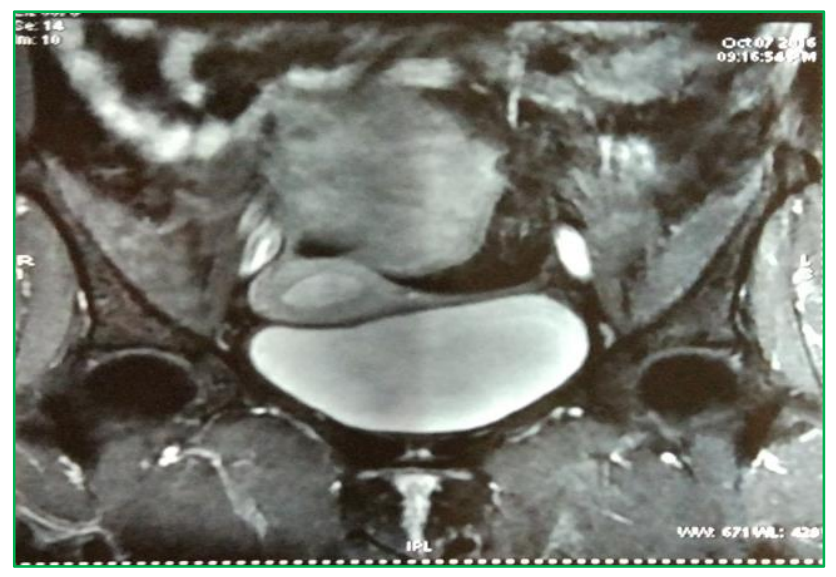

Figure 1: MRI showing large ovarian mass with normal sized uterus.

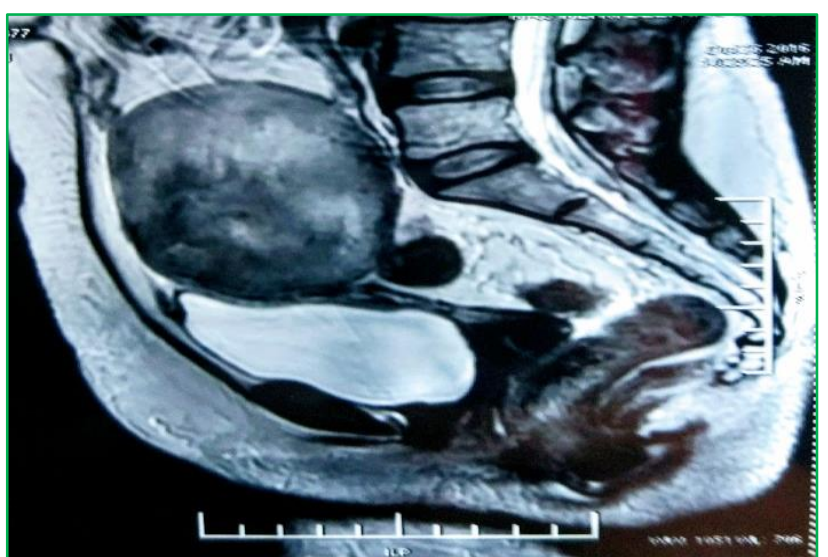

Figure 2: MRI showing ovarian mass on sagittal view.

Her whole abdomen and pelvic ultrasound findings showed right adnexal mass abutting right lateral wall of uterus. Uterus was normal in size and shape with endometrial thickness of $6 \mathrm{~mm}$. There was moderate ascites. No abnormality as noted in other visceral organs. Bilateral ovaries were not visualized. MRI whole abdomen showed large well circumscribed abdominopelvic mass lesion of $7 \times 9 \times 10 \mathrm{~cm}$ superior to uterine fundus and anterior wall of uterus and showed isointense signal intensity on $\mathrm{T} 1 \mathrm{~W} / \mathrm{T} 2 \mathrm{~W}$ sequences with internal areas of cystic degeneration which appears as hyperintense signal intensity on T2W/STIR sequence suggestive of right ovarian neoplastic lesion or broad ligament fibroid (Figure 1 and 2).

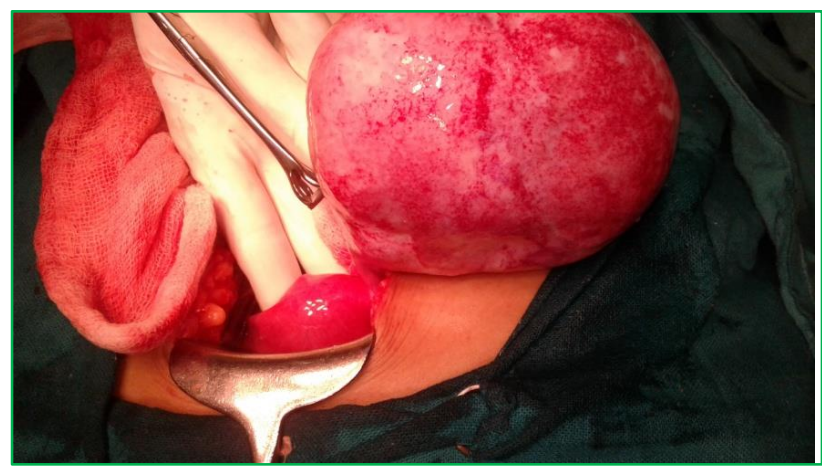

Figure 3: Per operative findings-large left side ovarian mass with normal sized uterus.

Keeping in view of her clinical history, examination and imaging, staging laparotomy was planned. Her routine investigations were normal. Staging laparotomy revealed $200 \mathrm{cc}$ of serous peritoneal fluid which was sending for cytology and biochemistry which came negative for malignancy. Uterus was normal size with no deposits. Right tubes and ovary were healthy, but ovary was streaked. Left ovary was streaked and at its medial end gave rise to a large solid ovarian mass of $8 \times 9 \times 10 \mathrm{~cm}$ which was adherent to rectosigmoid. On palpation, capsule was smooth, regular margins and intact (Figure 3 and 4 ). There were no deposits on mass.

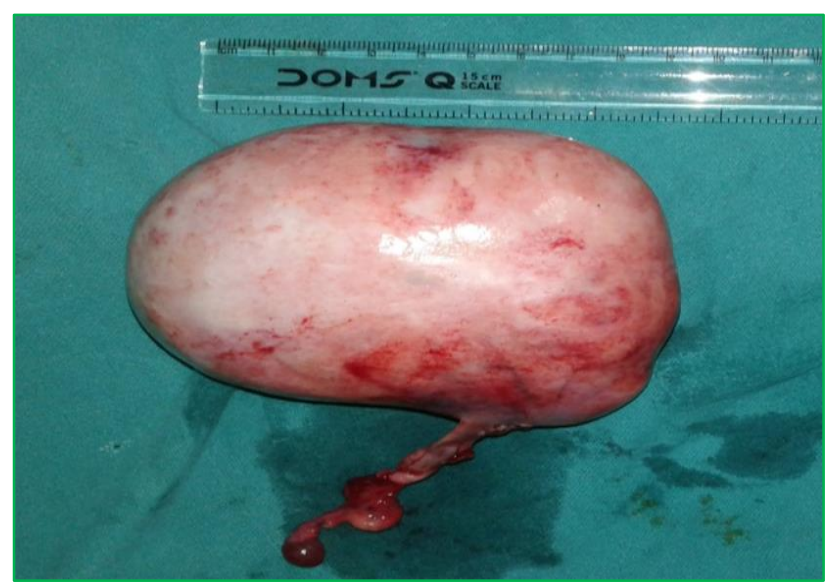

Figure 4: Per operative findings-gross appearance of ovarian mass.

Bowel was healthy and there were no enlarged lymph nodes. Left salpingo-oophorectomy was done as patient wished to retain uterus for future fertility options via invitro fertilization and staging laparotomy was suggestive of benign ovarian tumor. Patient had uneventful postoperative period and was discharged. 


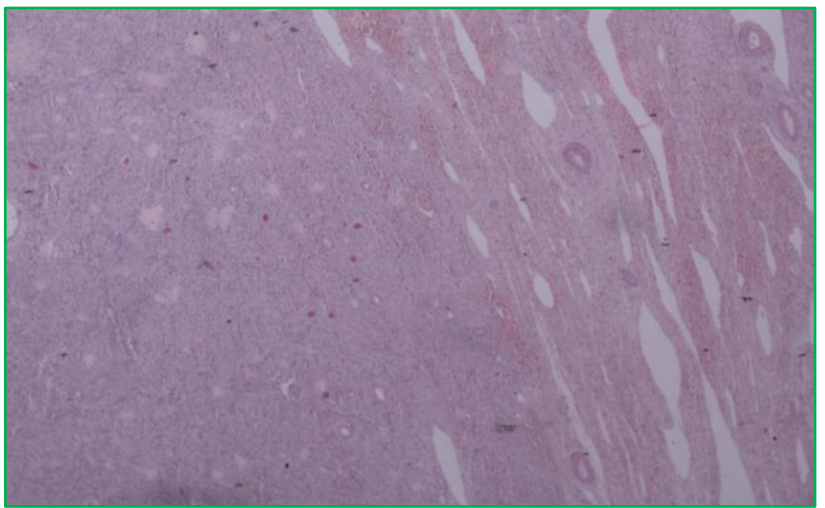

Figure 5: Histopathology showing ovarian tissue with follicles in periphery and smooth muscle fibres.

Omental biopsy was sent which was negative for any malignancy. Cut-section showed solid pattern suggestive of thecoma or fibroma. However final histopathology showed smooth muscle fibres with ovarian tissue at periphery suggestive of leiomyoma.

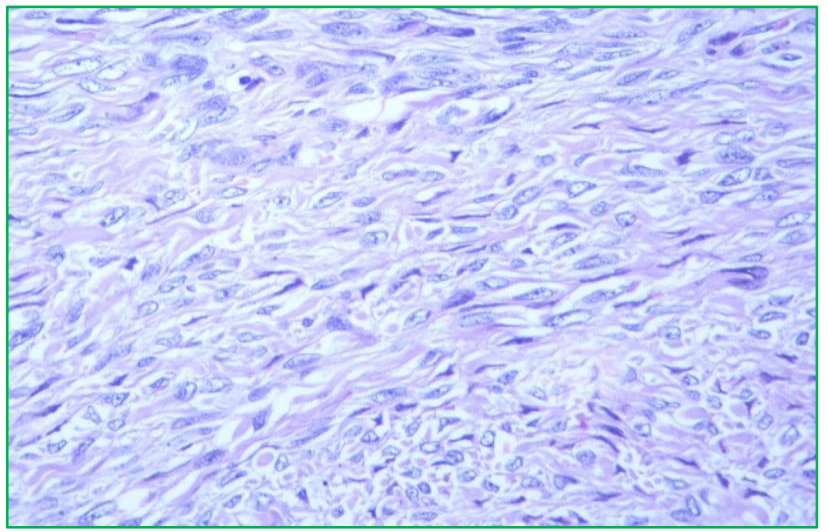

Figure 6: High power scan of same tissue.

There was no atypia or pleomorphism and increased mitotic count. Immunohistochemical staining showed strong and diffuse positive staining for smooth muscle actin (SMA) (Figure 5-8). Vimentin was strongly positive. Ki-67 proliferation index was low. Final diagnosis was primary ovarian leiomyoma.

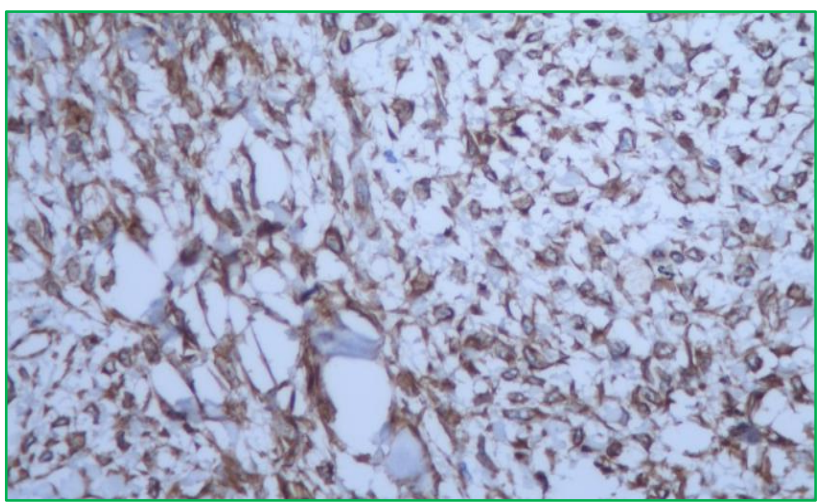

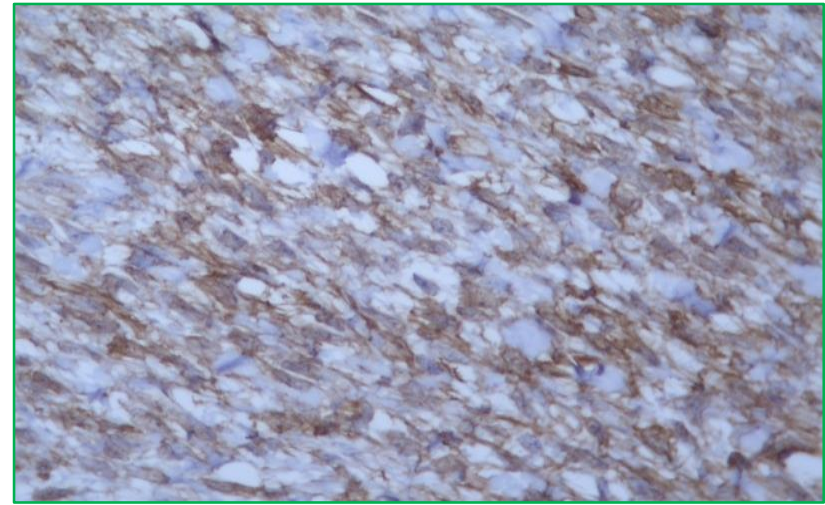

Figure 8: Strong positive SMA (Smooth Muscle Actin) stain.

\section{DISCUSSION}

Primary ovarian leiomyoma is a rare benign tumour of the ovary seen in women usually between 20 and 65 years old. ${ }^{1,4}$ Though it has been reported in premenarchal girl as well. ${ }^{3}$ Ovarian leiomyomas arise from smooth muscle cells in the ovarian hilar blood vessels, with other proposed origins being cells in the ovarian ligament, smooth muscle cells or multipotential cells in the ovarian stroma, and cortical smooth muscle metaplasia. ${ }^{1}$ oestrogen may play a role in the development of ovarian leiomyomas. These tumors are usually unilateral and small, but large sized tumors have also been reported, as in present case. ${ }^{7}$ In the pediatric/young adult group, they are commonly bilateral. ${ }^{4,8}$

They are detected incidentally during routine pelvic examination, during surgery, or after surgical removal of the ovary. 8 Most of the patients are asymptomatic or present as palpable mass, as in present case, with mild elevations of CA-125. In contrast, large tumors may present with ascites, hydrothorax, hydronephrosis, and elevated levels of tumour marker, CA 125. ${ }^{9}$ Ovarian leiomyomas often coexist with uterine leiomyomas, but in present case the uterus was normal in size and shape. Though fibroid is an estrogen dependent tumour, possible mechanisms of overgrowth in women in women with premature ovarian failure or postmenopausal women is due to possible ovarian cortical stromal hyperplasia leading to increased estrogen secretion in ovary contributing to development of ovarian fibroid. ${ }^{10}$

In the preoperative period, diagnosis can be difficult as ultrasonography visualises ovarian leiomyomas as ovarian solid tumours mimicking malignancy. Also due to large size it is difficult to distinguish mass from pedunculated or broad ligament fibroid or ovarian malignancy. MRI is often a useful adjunct to ultrasonography. In present case, MRI revealed isointense signal intensity on $\mathrm{T} 1 \mathrm{~W} / \mathrm{T} 2 \mathrm{~W}$ sequences with internal areas of cystic degeneration which appears as hyperintense signal intensity on T2W/STIR sequence

Figure 7: Strong positive vimentin stain. 
suggestive of right ovarian neoplastic lesion or broad ligament fibroid. ${ }^{11}$

Treatment options are hysterectomy with bilateral salpingo-oophorectomy in postmenopausal women. In premenopausal women, removal of the fibroid with ovarian preservation has been advocated. ${ }^{9,12}$ Present case was a premature menopause on account of premature ovarian failure, had mildly elevated CA 125 and rest of the tumor markers were negative. As it was a premature menopausal ovarian mass, authors kept malignancy as first differential and performed staging laparotomy. However, intraoperatively, ovarian mass appeared benign and as she was desirous of future fertility options, authors performed unilateral salpingo-oophorectomy preserving uterus and contralateral ovary. ${ }^{7}$ This patient was given medroxy progesterone acetate, following which she had a withdrawal bleed. Hence, she was enrolled in Invitro fertilization programme and is currently undergoing IVF treatment.

Final diagnosis of an ovarian leiomyoma is by histopathology showing smooth muscle fascicles and immunohistochemical analysis with diffuse strong positive staining for SMA, differentiating from thecoma as it does not express SMA. ${ }^{1,6,9}$ Ovarian leiomyomas must also be differentiated from leiomyosarcomas which has high the $\mathrm{Ki}-67$ proliferation index. ${ }^{13,14}$ present case had low Ki-67 proliferation index, was positive for SMA and vimentin, thereby confirming diagnosis of ovarian leiomyoma.

\section{CONCLUSION}

All early menopausal ovarian masses are not malignant in nature and ovarian and uterine conservation can be planned in absence of thickened endometrium.

Funding: No funding sources Conflict of interest: None declared

Ethical approval: Not required

\section{REFERENCES}

1. Taskin MI, Ozturk E, Yildirim F, Ozdemir N, Inceboz U. Primary ovarian leiomyoma: a case report. Int J Surg Case Rep. 2014;5:665-8.

2. Agrawal R, Kumar M, Agrawal L, Agrawal KK. A huge primary ovarian leiomyoma with degenerative changes: an unusual. J Clin Diagn Res. 2013;7(6):1152-4.

3. Blue NR, Felix JC, Jaque J. Primary ovarian leiomyoma in a premenarchal adolescent: first reported case. J Pediatr Adolesc Gynecol. 2014;27:e87-88.

4. Lim S, Jeon H. Bilateral primary ovarian leiomyoma in a young woman: case report and literature review. Gynecol Oncol. 2004;95:733-5.

5. Tomas D, Lenicek T, Tuckar N, Puljiz Z, Ledinsky M, Kruslin B. Primary ovarian leiomyoma associated with endometriotic cyst presenting with symptoms of acute appendicitis: a case report. Diagn Pathol. 2009;4:25.

6. Khaffaf N, Khaffaf H, Wuketich S. Giant ovarian leiomyoma as a rare cause of acute abdomen and hydronephrosis. Obstet Gynecol. 1996;87:872-3.

7. Güney M, Ozsoy M, Oral B, Mungan T, Kapucuoğlu $\mathrm{N}$. Unilateral primary ovarian leiomyoma in adolescent: a case report. Arch Gynecol Obstet. 2007;275:507-10.

8. Yasushi K, Noriyuki T, Masako S, Kaei N, Isao M. Magnetic resonance imaging findings in leiomyoma of the ovary: a case report. Arch Gynecol Obstet. 2005;273:298-300.

9. Koo YJ, Cho YJ, Kim JY, Lee JE, Kim ML, Kim $\mathrm{JM}$, et al. Ovarian leiomyoma as a potential cause of compromised fertility. Fertil Steril. 2011;95:1120.e11-4.

10. Doss BJ, Wanek SM, Jacques SM, Qureshi F, Ramirez NC, Lawrence WD. Ovarian leiomyomas: clinicopathologic features in fifteen cases. Int $\mathbf{J}$ Gynecol Pathol. 1999;18:63-8.

11. Mallick D, Saha M, Chakrabarti S, Chakraborty J. Leiomyoma of broad ligament mimicking ovarian malignancy- report of a unique case. Kathmandu Univ Med J (KUMJ). 2014;12(47):219-21.

12. Wei C, Lilic N, Shorter N, Garrow E. Primary ovarian leiomyoma: a rare cause of ovarian tumor in adolescence. J Pediatr Adolesc Gynecol. 2008;21(1):33-6.

13. Plewka A, Plewka D, Madej P, Nowaczyk G, SieronStoltny K, Jakubiec-Bartnik B. Processes of apoptosis and cell proliferation in uterine myomas originating from reproductive and perimenopausal women. Folia Histochem Cytobiol. 2011;49:398404.

14. Costa MJ, Morris R, DeRose PB, Cohen C. Histologic and immunohistochemical evidence for considering ovarian myxoma as a variant of the thecoma-fibroma group of ovarian stromal tumors. Arch Pathol Lab Med. 1993;117:802-8.

Cite this article as: Chaudhary V, Aggarwal K, Nangia A. Primary ovarian leiomyoma in young woman with premature ovarian failure. Int J Reprod Contracept Obstet Gynecol 2018;7:4301-4. 